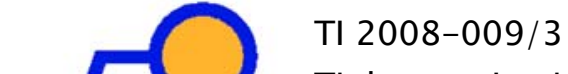

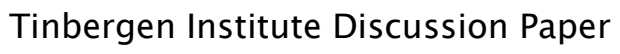 \\ Health and Income across the Life Cycle and Generations in Europe
}

\author{
Hans van Kippers/uis \\ Tom Van Ourti \\ Owen O'Donnel/2 \\ Eddy van Doorslaer
}

' Erasmus University Rotterdam, and Tinbergen Institute;

2 University of Macedonia, Thessaloniki, Greece. 


\section{Tinbergen Institute}

The Tinbergen Institute is the institute for economic research of the Erasmus Universiteit Rotterdam, Universiteit van Amsterdam, and Vrije Universiteit Amsterdam.

Tinbergen Institute Amsterdam

Roetersstraat 31

1018 WB Amsterdam

The Netherlands

Tel.: $\quad+31(0) 205513500$

Fax: $\quad+31(0) 205513555$

Tinbergen Institute Rotterdam

Burg. Oudlaan 50

3062 PA Rotterdam

The Netherlands

Tel.: $\quad+31(0) 104088900$

Fax: $\quad+31(0) 104089031$

Most TI discussion papers can be downloaded at http:/ /www.tinbergen.nl. 


\title{
Health and income across the life cycle and generations in Europe
}

\author{
Hans van Kippersluis ${ }^{a, b, *}$, Tom Van Ourti ${ }^{a, b}$, Owen O'Donnell ${ }^{c}$, \\ Eddy van Doorslaer ${ }^{\mathrm{a}, \mathrm{b}, \mathrm{d}}$ \\ a Erasmus School of Economics, Erasmus University Rotterdam, PB 1738, 3000 DR Rotterdam, The \\ Netherlands \\ ${ }^{b}$ Tinbergen Institute, Burgemeester Oudlaan 50, 3062 PA Rotterdam, The Netherlands \\ ${ }^{c}$ University of Macedonia, Thessaloniki, Greece \\ ${ }^{d}$ Department of Health Policy and Management, Erasmus University Rotterdam, PB 1738, 3000 DR \\ Rotterdam, The Netherlands
}

January, 2008

\begin{abstract}
An age-cohort decomposition applied to panel data identifies how the mean, overall inequality and income-related inequality of self-assessed health evolve over the life cycle and differ across generations in $11 \mathrm{EU}$ countries. There is a moderate and steady decline in mean health until the age of 70 or so and a steep acceleration in the rate of health deterioration beyond that age. In southern European countries and in Ireland, which have experienced the greatest changes in economic and social development, the average health of younger generations is significantly better than that of older generations. This is not observed in the northern European countries. In almost all countries, health is more dispersed among older generations indicating that Europe has experienced a reduction in overall health inequality over time. Although there is no consistent evidence that health inequality increases as a given cohort ages, this is true in the three largest countries - Britain, France and Germany. In the former two countries and the Netherlands, at least for males, the income gradient in health peaks around retirement age, as has been found for the US, but this pattern is not observed in the other countries. In most European countries, unlike the US, there is no evidence that income-related health inequality is greater among younger than older generations.
\end{abstract}

JEL Classification: D30, D31, I10, I12

Keywords: health, health inequality, life cycle, cohort

Acknowledgements: This paper derives from the NETSPAR funded project "Income, health and work across the life cycle". We are grateful to EUROSTAT and the UK Data Archive at the University of Essex for access to the ECHP and BHPS data, respectively. Further we thank the seminar participants at NETSPAR workshops, the $29^{\text {th }}$ Australian conference of health economists, the University of Melbourne and the Australian National University for comments on earlier versions of this paper. Tom Van Ourti is a Postdoctoral Fellow of the Netherlands Organisation for Scientific Research - Innovational Research Incentives Scheme - Veni.

* Corresponding author: Tel. +31-10-4088837, Fax: +31-10-4089141, hvankippersluis@few.eur.nl 


\section{Introduction}

How does the distribution of health evolve over the life cycle and is it changing across generations? How do socioeconomic disparities in health change as individuals age and are they narrowing, or widening, across generations? These questions are addressed using comparable panel data from 11 European countries. The analysis is pertinent not only to gauging the consequences of the rapid population ageing occurring in Europe and elsewhere, but also to determining the causes of the socioeconomic gradient in health and the extent to which European countries have been successful in reducing such disparities over time. Knowledge of how the distribution of health changes over the course of the life cycle is key to understanding individual behaviour with respect to retirement, saving, health insurance and the utilisation of health care, and, consequently, to the formation of public policy concerning pensions, health financing, and health and social care. Evidence of generational differences in health is essential for accurate monitoring and projection of trends in population health, and can signal potential determinants of health, such as living conditions in childhood.

Beyond a certain age it is anticipated that health will begin to decline. But at what age, on average, does this decline set in? What is the rate of decline? And from which age does this accelerate such that the deterioration in health becomes rapid? The answers to these questions have important implications for a wide range of policies including, for example, increases in the retirement age that are being implemented, or considered, in a number of European countries. Besides identifying the average rate of change in health across the life cycle, it is also important to establish whether health becomes more or less dispersed as a cohort of individuals ages. Deaton and Paxson (1998) argue that if shocks to health are permanent, then their cumulative effect will result in health being more widely dispersed at older ages. In this case, there would be welfare gains from pooling risks across periods to provide protection against the cumulative deterioration of health, or at least its financial consequences, but these may not be realisable given the enforceable insurance contracts currently offered by markets (Diamond, 1992; Cochrane, 1995; Pauly et al., 1995). Divorcing health financing contributions from risks, as is done in most European social insurance and tax financed systems, may partially solve this problem but relies on within, as well as between, generation solidarity that could become increasingly strained as a cohort ages and redistribution from the healthy to the unhealthy increases. A further implication if health dispersion does indeed increase with age is that ageing of the population would lead to 
greater total inequality in health, providing there were no offsetting differences across generations.

The existence of socioeconomic inequality in health in Europe and elsewhere is firmly established (Adler et al., 1994; van Doorslaer et al., 1997; Mackenbach et al., 1997; Smith, 1998, 1999; van Doorslaer and Koolman, 2004), but its causes are not yet well understood. Examination of how the socioeconomic gradient in health varies across the life cycle can help reveal its origins (Case et al., 2002; Smith, 2005a; Currie et al., 2007). For example, there is some US evidence of the gradient peaking around retirement age (Elo and Preston, 1996; Smith and Kington, 1997; Deaton and Paxson, 1998; Smith, 2005b). This is consistent with the gradient in large part reflecting income losses from illness-induced interruptions to work, which obviously cease after retirement. While a couple of European studies confirm this inverse U-shape in the age profile of the health-income gradient (Van Ourti, 2003; Kamrul Islam et al., 2007), others show that it continues to prevail post retirement (Gerdtham and Johannesson, 2000; Burström et al., 2005), albeit less so for an occupation based measure of socioeconomic status (Marmot and Shipley, 1996), and even to increase in early old age (Chandola et al., 2007). This is relevant to an ongoing debate, to which we aim to contribute, over whether the relationship between health and socioeconomic status follows a process of cumulative advantage, with early life disparities in health becoming magnified over the life cycle (Ross and Wu, 1996; Lynch, 2003; Wilson et al., 2007; Kim and Durden, 2007), or whether health problems that inevitably arise in the course of time act as a leveller and so narrow socioeconomic disparities in old age (Kunst and Mackenbach 1994; Elo and Preston 1996; Deaton and Paxson 1998; Beckett 2000; Case and Deaton 2005; Herd 2006; Kim and Durden, 2007).

The distribution of health may differ between generations because of changes in the health system, such as the extension of coverage, or advances in medical technology that are effective for the treatment of age-specific conditions. Differences in the health, economic and social conditions experienced in early childhood are also potentially important contributors to inter-generational differences in health. There is considerable evidence supporting a strong link between early childhood, even intrauterine, experiences and health in later life (Barker, 1995; Case et al., 2005; van den Berg et al., 2006; Bozzoli et al., 2007). The socioeconomic gradient in health may differ across generations in response to changes in wider social and economic disparities (Pappas et al., 1993; Preston and Elo, 1995; Deaton and Paxson, 1998). These cohort effects potentially confound age effects, but they are also of interest in their own right. Not least for the purpose of predicting the consequences of population ageing, one 
wants to know whether younger generations are, on average, healthier than older generations, whether health inequality is increasing or decreasing, and whether the socioeconomic gradient in health is becoming more or less steep over time.

In this paper we describe how the distribution of health and income-related health inequality evolve over the life cycle and differ across generations in 11 European Union (EU) countries. This is the first study to disentangle age and cohort effects for the mean level of self-assessed health, as well as for overall and income-related health inequality, across a large number of European countries. It enables us to establish whether the life cycle evolution of health and its socioeconomic gradient are consistent across countries. Any observed differences in the age profiles may reflect differences in welfare systems and their consequences for the way in which age, health and income interact. The 11 countries studied span the north and south of Europe and so differ in the scale and timing of the economic and social development, as well as changes in public health and nutrition conditions, experienced over the lives of the adults represented in the data. We examine whether this heterogeneity is reflected in the size and nature of generational differences in the distribution of health.

The analysis is closely related to that of Deaton and Paxson (1998), who describe how average self reported health, its variance and its correlation with income vary with age in US cohorts. They find that average health declines with age at a surprisingly constant rate. This finding is confirmed for Britain by Sutton (2004) and for Sweden by Burström et al. (2005). The US and European studies are less consistent with respect to the direction of the cohort effect. Deaton and Paxson (1998) find that average health is lower for older cohorts but there is no difference between cohorts born after 1945, while Sutton (2004) and Burström et al. (2005) find that younger cohorts report lower health.

Deaton and Paxson (1998) find that the variance in health is increasing up to the age of 60, after which it remains constant. This is only partially consistent with their prediction that, if health shocks are permanent and not perfectly correlated across individuals, then the variance should be monotonically rising with age for a fixed cohort of individuals. The incomplete empirical verification may be due to selective mortality but it could also indicate invalidity of the assumptions made about the evolution of health. Deaton and Paxson assume that health shocks are additive and independent, and so health follows a random walk. If instead one assumes multiplicative shocks deriving from the depreciation of health capital (Grossman, 1972), then the prediction of increasing variance with age no longer holds. ${ }^{1}$ We add to Deaton and Paxson's previously sole analysis of the relationship between age and the variance of health with the purpose of improving understanding of how health evolves over 
the life cycle. We also seek to establish whether Deaton and Paxson's finding of a smaller variance among later born cohorts, indicating that the distribution of health in the US is becoming more compressed, is confirmed for European countries.

Deaton and Paxson (1998) find that the income gradient in health is greater among younger cohorts in the US, such that socioeconomic inequality in health has been rising while total health inequality, measured by the variance, has been falling. Kamrul Islam et al. (2007) find that socioeconomic inequalities in reported health have been increasing over time in Sweden, but Ferrie et al. (2002) and Burström et al. (2005) find little or no evidence of

increasing socioeconomic inequality in morbidity in the UK and Sweden respectively. ${ }^{2}$ We substantially extend the evidence on how socioeconomic inequality in health is changing across Europe through analysis of common measures of health and income from $11 \mathrm{EU}$ countries.

The remainder of this paper is organized as follows. Section 2 describes the data and the measurement of health using utility scores to scale self-reported health categories. This procedure avoids the assumption, made by Deaton and Paxson (1998), that health declines linearly across categories and results in a more plausible age profile of health. The implications for the measurement of health inequality are also discussed here. Section 3 presents the methodology for separating age from cohort effects using the panel data. In section 4 we present the results and in section 5 their robustness is checked to different aspects of the methodology. In the final section we summarise the results and discuss their implications.

\section{Data and measurement of health}

We use data taken from the full eight waves (1994-2001) of the European Community Household Panel (ECHP). The ECHP was designed and coordinated by the European Statistical Office (EUROSTAT). It consists of a panel of households providing data on socioeconomic, demographic and health characteristics of individuals aged 16 or older. We restrict attention to adults aged 18 and above. The questionnaire is standardized across all countries. We use all waves that are available for 11 EU member states: Belgium, Denmark, France, Germany, Greece, Ireland, Italy, the Netherlands, Portugal, Spain and the United Kingdom. Luxembourg is not included due the small size of the sample and Austria, Finland and Sweden are not analyzed due to the limited number of available waves (respectively 7, 6 and 5). For Germany and the UK, we do not use the original ECHP samples (which only ran 
for the first three waves) but instead use the corresponding waves from the German Socioeconomic Panel (GSOEP) and the British Household Panel Survey (BHPS). ${ }^{3}$ One wave (9) of the BHPS is dropped because of an inconsistency in the health question (Hernández-Quevedo et al., 2007) and the 2002 wave (12) is added as a replacement. As a result, we analyse exactly eight waves for all countries. Table A.1 in the appendix lists the sample sizes and some descriptive statistics from the data. All analyses are conducted separately for each of the 11 countries.

The two key variables in the analysis are health and income. The ECHP income measure is annual disposable (i.e. after-tax) household income, including income from work, investments, property, private transfers, pensions and other direct social transfers. Indirect social transfers (e.g. reimbursement of medical expenses), in kind benefits and imputed rent from owner-occupied accommodation are not included. Income is divided by the OECD modified equivalence scale in order to account for differences in household size and composition. ${ }^{4}$ In the BHPS an additional file is used to derive the annual disposable income (Bardasi et al., 2007). Concerns about the appropriateness of disposable income as an indicator of the living standards of the elderly (see e.g. Van Ourti, 2003; Fahey et al., 2004) are less worrisome here as it is only used to rank individuals within cohorts/generations.

Information on health is from the question, “How is your health in general?” with a fivepoint response scale ranging from very good to very bad. A potentially important difference in the UK is that the BHPS question instructs respondents to rate their health relative to others of the same age. ${ }^{5}$ This self-assessed health (SAH) variable is widely used and is known to be a very good predictor of other health outcomes including mortality (see e.g. Idler and Benyamini, 1997). One important drawback is that it is ordinal and so computing descriptive statistics directly from it, using a scale of 1 to 5 for example, implicitly assumes movements between subsequent SAH categories always represent the same change in health. This is a strong assumption. It has been shown that the profile across SAH categories of other selfreported cardinal measures of general health is concave with the health difference between very good and good SAH being smaller than that between good and fair (see Van Doorslaer and Jones, 2003).

To allow for such concavity we transform the ordinal SAH information onto a cardinal scale. Utility scores for the SAH categories are taken from the 2001 Canadian Community Household Survey (CCHS), which is a large scale household survey that contains data on both the five-point SAH question available in the ECHP and a general health measure with a cardinal scaling - the Health Utility Index Mark 3 (HUI3) (Furlong et al., 2001; Feeny et al., 
2002). The HUI3 uses a multi-attribute function to transform an individual's health status measured on eight domains into a utility score derived from community preferences over health states (Furlong et al., 2001; Feeny et al., 2002). The index has interval scale properties and is scaled such that a value of 0 represents death and 1 indicates perfect health. We attach the SAH category specific means of HUI3 computed from the Canadian sample to the respective SAH categories in the ECHP data. Obviously this is somewhat restrictive in that it does not allow for any differences between the EU countries and Canada in the profile of mean health utility across SAH categories. But this is no more restrictive than imposing the same arbitrary scale on SAH categories across all countries and there is no information available that would allow the scale to differ across countries. Moreover, a multi-attribute utility function estimated from French data proved to be very similar to the original function estimated from the Canadian data (Le Galès et al., 2002).

The interval scale property of the HUI3 has consequences for the summary statistics used to measure overall and income-related health inequality. The concentration index has been a popular measure of income-related health inequalities (Wagstaff et al., 1991; van Doorslaer et al., 1997), but in a recent contribution Erreygers (2006) has shown that its validity crucially depends upon the scaling of the underlying health variable. If the scaling is interval (as is the case for the HUI3), the concentration index will have the following undesirable properties: (i) its bounds will depend on the minimum, maximum and average value of health, (ii) its value will differ depending upon whether health (HUI3) or ill-health (i.e. one minus HUI3) is examined, and (iii) its value will not be invariant to a positive linear transformation. These properties may obscure the life cycle profile and generational differences in income-related health inequality. For example, the first property implies that the life cycle profile of average health will influence the life cycle profile of the concentration index; and the third property implies that changing the location of the HUI3, which is essentially arbitrary, may change the generational differences in the concentration index. Using an axiomatic approach, Erreygers (2006) derives an adjusted concentration index that does not have these drawbacks, but preserves other desirable properties of the concentration index as a measure of income-related health inequality. ${ }^{6}$ A similar argument holds for measures of total health inequality. For example, the variance, the coefficient of variation and the Gini index all require that the underlying health variable has ratio scale properties. Application of one of these three measures to the interval scaled HUI3 leads to the same three undesirable properties. Erreygers (2008) develops an adjusted Gini index that does not have these deficiencies. It is similar to the adjusted concentration index, except that individuals are 
ranked by health, rather than income. The issue does not arise for mean health. Although mean health is only uniquely defined up to a positive linear transformation of the interval scaled HUI3, its life cycle profile is not affected. The latter follows from the fact that the mean of a positive linear transformed variable equals the positive linear transformation of the mean, which is not the case for the traditional measures of total and income-related health inequalities. ${ }^{7}$

For a given SAH category, older individuals tend to have lower health as measured by HUI3 (Lindeboom and van Doorslaer, 2004). It is likely that this reflects both the inability of a crude ordinal measure such as SAH to capture all the variation in health and age differences in the thresholds of true health at which health is reported to be very poor, poor, etc (ibid). To allow for variation in HUI3 by age and sex within SAH category, and so simultaneously correct for age-sex heterogeneity in reported SAH, we assign the SAH category, age-sex specific means of HUI3 from the Canadian data to ECHP observations within the respective SAH category. Figure 1 illustrates, using the CCHS data for males, the impact on age profiles of applying age-sex specific HUI3 scores to the SAH categories. Profiles are presented for the measures of health's central tendency (mean), total inequality (adjusted Gini) and income-related inequality (adjusted concentration index). ${ }^{8}$ For each statistic, the age profile is presented for SAH categories scaled using: (i) 1 (very bad) to 5 (very good), as in Deaton and Paxson (1998), (ii) category means of HUI3, (iii) category and age-sex specific means of HUI3. A fourth graph for each statistic shows the profile using the actual HUI3 score for each observation.

Using the simple 1-5 scaling of $\mathrm{SAH}$, the profile shows a rather implausible near linear decrease in mean health with age. This is similar to what was found by Deaton and Paxson (1998). Using the SAH category specific HUI3 scores has little impact on the profile for mean health but when age-sex specific scores within each SAH category are used the profile displays greater concavity indicating, as seems plausible, that mean health declines more rapidly at older, than at younger, ages. ${ }^{9}$ We conclude that SAH alone is too crude a measure to capture the age profile of mean health but scaling it by age-sex specific utility scores yields plausible results. For the adjusted Gini, moving from the 1-5 scaling of SAH to age-sex specific utility scores within each SAH category brings the age profile closer to that obtained from the observation specific utility scores. But, of course, the magnitude of the dispersion can never reach that obtained from the individual specific scores. At any given age, the adjusted Gini using the age-specific HUI3 scores is about three times smaller than 
that obtained from the actual scores. The age profile of the adjusted concentration index is less sensitive to the method of scaling SAH.

[insert Figure 1 about here]

\section{Decomposition of age and cohort effects}

The longitudinal nature of the ECHP makes it possible to perform a true cohort analysis. Following the same individuals over time identifies the age effect by observing how their health changes as they age. In order to identify the cohort effect, we group observations by birth year intervals and compare, for example, mean health of two cohort groups at the same age across different waves. This is done through cohort level regression analysis, as in Deaton and Paxson (1998). This avoids the imposition of any restrictions on the nature of the age and cohort effects at the individual level, which would be unavoidable if the regression analysis were conducted at that level.

Although, ideally, one would construct a cohort specific to each birth year, this would result in too few observations per cohort in each wave. Instead, we construct 13 cohorts of five-year birth intervals. Since there are very few observations in the oldest cohorts we exclude individuals born before 1912. It follows that the youngest cohort was born within the period 1972-1976, with an average age of 20 in the first wave and ages on average to 27 in the last wave. The oldest cohort was born between 1912 and 1916, with an average age of 80 in the first wave and 87 in the last.

It is the ageing over time within a cohort that identifies the age effect. The cohort effect is identified through comparison between consecutive cohorts at three overlapping ages across waves. This is illustrated in Table 1. The youngest cohort ages on average from 25 to 27 during the last three waves of the panel and can be compared with the second cohort that covers this average age span over the first three waves. Likewise, the second and third cohorts both span the 30-32 age range during the last and first three waves respectively.

[insert Table 1 about here]

We compute each of the three statistics - mean, adjusted Gini index and adjusted concentration index-for SAH category, age-sex specific HUI3 scores (hereafter referred to as scaled $S A H$ ) for each cohort in each wave and estimate both the age and cohort effects by 
regressing each statistic on a full set of age and cohort dummies. Because it is likely that health dynamics differ across sexes, all analyses are performed separately for males and females. These regressions are based on 104 observations, i.e. 8 waves times 13 cohorts. We use a separate dummy for each cohort, but the construction of the age dummies is more subtle. We need to ensure that the age range captured by any given age dummy does not span more than one cohort defined by a five-year birth interval. Single year age dummies would, of course, suffice but leave too few degrees of freedom. Instead, we enter a combination of one and two-year age dummies to indicate the average age of each cohort in each wave. ${ }^{10}$

Consistent with the cohort nature of the analysis, we use all observations present in the first wave (1994). ${ }^{11}$ The 1994 cross-sections are made representative of the populations in that year through application of the ECHP first wave sampling weights (Eurostat, 2003). To keep subsequent waves of the unbalanced panel representative of the 1994 populations, and so deal with health related attrition that has been found in these data (Jones et al., 2006), we construct and apply attrition corrected weights. For all wave 1 observations, we use probit regressions to predict the probability of remaining in the sample at each of the subsequent waves as a function of the following wave 1 explanatory variables: sex, income, household composition, thirteen 5-year age dummies, five SAH dummies and an interaction between $\mathrm{SAH}$ and age. The wave 1 ECHP provided sampling weights are then multiplied by the inverse of these (wave specific) predicted probabilities and, for each wave, this product is used to weight each observation in the calculation of the three statistics of interest. These statistics are regressed on the set of age and cohort dummies using OLS.

\section{Results}

Before presenting the main results we show how each of the three statistics of interest differ by age without disentangling the life cycle and cohort effects. This serves as a point of reference against which to gauge the effect of making the age-cohort decomposition. In Figure 2, we present for each age group the mean, adjusted Gini index, and adjusted concentration index of scaled SAH, separately for males and females. These age profiles derive from straightforward regressions with only age dummies. ${ }^{12}$ The point estimates, presented with 95\% percent confidence intervals, show differences from the reference category of 20-24 years. Intercepts are not shown in the graphs to facilitate cross-country comparison of the curvature of the age profiles, and not their levels which are potentially more prone to cross-country reporting heterogeneity. Countries are arranged geographically 
by northern and southern Europe, with Ireland included in the latter group because it bears closer resemblance to those countries with respect to the main results presented below.

For all three statistics, the unadjusted age profiles display a remarkable degree of consistency across countries. In most countries, there is little difference in mean health over the age range of 20-40, between 40 and 70 there is a steady decrease in health and this becomes much steeper above the age of 70. The deterioration of health with age is less steep in the UK, the Netherlands, Belgium, Denmark and Ireland than in other countries. For the UK, it seems likely that this is due to the different wording of the BHPS SAH question that asks respondents to rate their health relative to others of the same age. The adjusted Gini index of health seems to increase with age in all countries and the rise is most pronounced at higher ages. The increase is shallower in Belgium, Denmark, Ireland, the Netherlands and the UK. In most countries, the adjusted concentration index increases with age, reaching its peak in the age range in which most people retire (i.e. 55-65) before decreasing. Another striking observation from these graphs is that the age profiles for males and females show very little difference, especially for the mean and the adjusted Gini index. For the adjusted concentration index, gender differences are somewhat larger. For males there is often a clear peak around retirement age, while for females the pattern is more gradual, and the peak often occurs somewhat earlier.

[insert Figure 2 about here]

In Figure 3, we present the life cycle (light) and cohort (dark) profiles for each of the three statistics that derive from the age-cohort regression analysis described in the previous section. Again we present coefficients, which show deviations from the reference age (20-24) and cohort birth-year (1972-76) groups. For example, when the cohort profile for the mean lies below the horizontal at zero, it implies that earlier born cohorts experience worse health at any given age. For every country, tests strongly confirm the joint significance of all the age dummies and of all the cohort dummies for both the mean and the adjusted Gini index (see Appendix Table A.2). For the adjusted concentration index, both the age and the cohort dummies are jointly significant, usually at much less than 5\%, in every case but for the cohort dummies for females in Greece and Spain, and the age dummies for males in Germany.

For mean health, in general, the life cycle profiles differ little from the unadjusted age profiles presented in Figure 2. Health changes little as individuals age between 20 and 40. From the age of forty health begins to decline but there is often a levelling, or even an 
improvement in health between 55 and 65. The flattening of the profile around retirement age has been observed in other studies (e.g. Deaton, 2007). Deaton (ibid) conjectures that it could result from the pre-retirement group being particularly intolerant to the onset of health problems. This may be motivated by the incentives created by disability insurance in the preretirement age range. More optimistically, it could reflect a positive impact of retirement on health—a 'honeymoon phase' (Atchley, 1976).

Beyond the 65-70 years age range, health begins to deteriorate rapidly. In a number of countries, the degeneration of health appears to be even more compressed into the advanced years once control is made for differences in health across generations. Comparison between Figures 2 and 3 confirms that this is true for Greece, Ireland, Italy, Portugal and Spain. These differences in the age profiles reflect strong cohort effects in these (mostly) southern European countries, which are observable in Figure 3. In each of these countries, older generations have markedly worse health than their younger counterparts (at a given age). Horsman et al. (2003) estimate a difference in HUI3 of 0.05, or more, to represent a clinically important change in health. Usually the health difference between the youngest and oldest cohort is around 0.1 , so this is a substantial improvement in health over generations. Notably, four of these countries are southern European and the fifth, Ireland, has also experienced very rapid economic and social development over the period spanned by the lives of the adults represented in these data. It is conjecture, of course, but it seems plausible that the generational differences in health we observe reflect the advances that have been made in these countries over the post-war era. In most of the northern European countries (Belgium, Denmark, France, Germany and the Netherlands) the cohort effects are jointly significant, but there is no evidence of any clear improvement or deterioration in average health across generations. In the UK generations born before 1930 for males and 1940 for females actually report significantly better health, on average, than more recently born cohorts. This is surprising given gains that have been recorded in objective indicators of population health, such as life expectancy. It may reflect generational differences in health expectations that confound the reporting of health, or it could be an artefact stemming from the reference to age in the BHPS SAH question, although one would expect the latter to affect the age profile more than the cohort profile.

With few exceptions, there is an upward gradient in the cohort profile for the adjusted Gini index indicating that health is more dispersed among older generations. This is consistent with what Deaton and Paxson (1998) found for the US. The tendency towards reduced inequality in health among younger generations is strongest in the countries that also 
show an improvement in average health (Greece, Ireland, Italy, Portugal and Spain). In the northern, more industrialized countries, particularly in France, Germany, the Netherlands, the compression of the health distribution among younger generations is less pronounced. The UK is the only country in which there is less health inequality among older cohorts although only significantly for females - which again might be related to the age reference in the SAH question.

There is less consistency across countries in the life cycle profiles of the adjusted Gini index. The tendency for inequality to increase with age that was observed for all countries in Figure 2 appears to be driven by the cohort effects. Once these are controlled for there is evidence that health becomes significantly more unequally distributed as individuals age only for France, Germany, Dutch females and the UK. For these countries the evidence is even stronger than that found for the US by Deaton and Paxson (1998) in support of their hypothesis that the variability of health increases over the life cycle due the cumulative effect of permanent health shocks. But in the remaining countries, the life cycle profile of the adjusted Gini index displays a variety of patterns after the age of 50 and is actually significantly decreasing with age in Spain and for females in Ireland. There is no emergence of a stylised fact that health consistently becomes more unequally distributed as a cohort ages.

After taking out the cohort effect, the adjusted concentration index continues to show some sign of peaking around retirement age only for British, Dutch, French, and Irish males and Danish females. But the precision is low, indicated by wide confidence intervals, and the profiles could not be described as having a distinct inverted U-shape. In a few cases incomerelated health inequality is increasing over the life-cycle (Greek males and Dutch females) and in Italy it is falling. In most countries, particularly for females, the cohort profile of the adjusted concentration index is flat. Unlike what Deaton and Paxson (1998) found for the US, there is little evidence from Europe that the income gradient in health is becoming steeper among younger generations. There is evidence that this is occurring only among Dutch females. For many of the others, if anything, the trend is in the opposite direction. But it is evident that the confidence intervals for the concentration index are often substantially wider than those for the other statistics and this might reflect a difficulty in separately identifying the age and cohort effects for this statistic.

[insert Figure 3 about here] 


\section{Robustness checks}

In this section we check the robustness of the results to allowing for possible period effects and extending the number of waves to better disentangle age from cohort effects. All results are available on request from the authors.

\subsection{Allowing period effects}

The regressions underlying Figure 3 do not allow for any period effects. That is, variation in health from year-to-year that is common to all ages and cohorts. Period effects are not taken into account in the basic analysis for two reasons. First, it seems likely that any common year-to-year variation in health over the span of eight years is much less important than age and cohort differences. Second, it is well known that unrestricted age, cohort and period effects cannot all be separately identified (Weiss and Lillard, 1978) and, even with restrictions, it might be overly ambitious to attempt to disentangle all three effects from only eight years of data. Yet, period effects on the distribution of health certainly cannot be ruled out entirely a priori. They could derive from a business cycle effect operating through labour market conditions, levels of stress, consumption of alcohol or accidents (Ruhm 2003 and 2004). Any changes in disability insurance eligibility rules may also affect the reporting of health. It is also possible that innovations in medical technology over the period of the study could impact on the distribution of health, although it seems unlikely that our health measure is sufficiently sensitive to pick this up.

Since we are intrinsically interested in the age and cohort effects and we expect the period effects, if any, to mainly derive from business cycle fluctuations, it seems most appropriate to achieve identification by constraining the period dummies to be orthogonal to a linear time trend (Deaton, 1997). This essentially ensures that all trends in the data are attributed to the cohort and age effects. The interpretation is now of a fixed age profile, a cohort-shift in this profile and period effects stochastically moving the data off the profile. Practically, with the orthogonality constraint and restricting the coefficients of the period effects to sum to zero, this boils down to estimating the regression with six period dummies, defined as in Deaton (1997).

For most countries and statistics, the period dummies were not significant (especially for males). ${ }^{13}$ In any case, the inclusion of period effects lowered the precision of the estimates of the age and cohort effects greatly, while the patterns of the age and cohort profiles remained similar. 
Since our time frame is rather short, making it difficult to separate cycles from a trend, we also experimented with year specific macroeconomic indicators-GDP growth and the unemployment rate- to capture any business cycle effect. Using Belgium as a test case, the regression analyses were repeated with the addition of each of the two macro indicators separately and jointly. The addition of GDP growth had a similar impact on the point estimates to the inclusion of the restricted period dummies, but without inflating the confidence intervals as much. Only for the mean health of females was GDP growth significant. Adding the unemployment rate to the regression had a larger impact on the age coefficients for all statistics, although it was significant only in the regression of the concentration index for females. It appears that this variable is competing with age to pick up the over time variation, leading to a distorted age profile. Including both indicators gave equivalent results as adding the unemployment rate to the regression.

Since allowing for period effects, either through dummies or macro indicators, reduces the precision of the estimates while leaving the age and cohort profiles much the same, we prefer the more parsimonious specification.

\subsection{Extending the number of waves}

All the analyses use eight waves of data taken from the ECHP for most countries and from the BHPS and GSOEP in the cases of the UK and Germany. The latter two panels run for more than eight waves, providing an opportunity to examine whether eight waves are sufficient to adequately identify age and cohort effects. For the UK, we repeated the analysis using 13 waves of the BHPS (1991-2004). While with eight waves the cohort effects are identified through the comparison of two adjacent cohorts at common ages across waves, with 13 waves it is possible to compare three different cohorts at the same age. As anticipated, this resulted in more precise estimates of the age and cohort profiles. But the shapes of these profiles hardly changed, except for the age profile of the adjusted concentration index for males which is no longer significant. This supports our warning at the end of section 4 that it appears more difficult to separately identifying the age and cohort effects for the adjusted concentrated index. Overall though, our findings suggest that an eight year time span is sufficient to identify the patterns of the age and cohort effects. 


\section{Conclusion}

In the context of ageing European populations, it is vital to identify both how the distribution of health evolves as individuals age and also how it is changing across generations. Revelation of the life-cycle profile of health is crucial to improved understanding of individual decisions concerning saving, health insurance and retirement, for example, and also to establishing needs for medical and long-term care. A cross-sectional analysis of the relationship between health and age does not suffice as this age profile is confounded by generational differences in the distribution of health. These cohort effects are not simply a nuisance, but tell us how the distribution of health has evolved over decades. Disentangling cohort effects from the 'pure' age effect is not only important for mean levels of health, but also for health inequality, both overall and socioeconomic. If health inequality is increasing over the life-cycle, then mechanisms, such as social insurance, that pool risks across periods offer welfare gains over sequential, single-period insurance contracts. If part of any permanent change in health remains private information, then multi-period contracts offered early in life would also face less adverse selection. Of more immediate interest is whether European countries have been successful in reducing both total and socioeconomic inequalities in health such that, within younger generations, health is less dispersed and less closely associated with income than it is among older generations. Finally, examination of how income-related health inequality varies across the life cycle can help point to the mechanisms that lie behind this gradient.

Not surprisingly, we find average health to decline with age. More interesting is the consistency in the pattern of this decline. In most countries, there is a gradual but steady fall in mean health from early adulthood until around the age of 50. The deterioration in health generally levels off in middle-age before accelerating rapidly beyond the age of 70 . Deaton and Paxson (1998) found a less plausible linear decline in health in the US, most probably because they did not scale SAH responses to reflect the magnitudes of differences in health between categories. The middle-age plateau in the profile of mean health is rather puzzling. It may simply be an artefact of the insensitivity of SAH to changes in health in this age range, although the use of age-sex specific HUI3 scores within each SAH category makes this less likely. The decline in mean health between the ages of 70 and 80 is generally around 0.15 on the HUI3 scale, which is substantial given that a change of 0.05 is considered clinically significant (Horsman et al., 2003). This rapid deterioration suggests that while health might not be a significant physical constraint on raising the retirement age toward 70, currently it 
would be a substantial constraint beyond that age. Of course, few individuals will wish to work until their health makes it physically impossible to continue and so the expected rapid decline in health after 70 may encourage individuals to retire well before that age while their health still permits them to enjoy their increased leisure time. While these issues are central to the debate currently being conducted in many European countries in response to proposals to raise the retirement age, we should be careful not to overstep the implications that can be drawn from our descriptive analysis. We have identified how health changes on average with age but not why it does so. We do not know what role retirement itself plays in determining the age at which health begins to decline rapidly. It could well be that a rise in the retirement age would shift the age profile of health, although whether it would be most likely to shift outward or inward is difficult to establish from the current evidence (Charles, 2002; Shan et al., 2005; Neuman, 2007).

The retirement age is seldom, if ever, increased for the generation currently approaching it. Assessment of whether population health is likely to be a constraint on this policy therefore requires knowledge of the extent to which the age profile of mean health is shifting out for younger generations. Our results indicate that this is happening in southern Europe and in Ireland but not in northern Europe. The groupings of countries are consistent with anticipated differences in the timing of health benefits from improved nutrition, living conditions and access to medical care over the course of the last century and also with evidence on cohort differences in adult height across Europe (Garcia and Quintana-Domeque, 2007). Garcia and Quintana-Domeque find that the same four southern European countries that are included in the present study, plus Ireland, experienced increases in mean height much later than northern European countries. Bozzoli et al. (2007) confirm this finding and demonstrate that the post neonatal mortality rate is negatively and strongly correlated with the mean height of a cohort in adulthood. This is consistent with a strong life-long impact of health conditions experienced in infanthood (Barker, 1995; Case et al., 2005; Van den Berg et al., 2006). It suggests that the gains in adult health for younger generations that are observed in the ECHP data for the four southern European countries and Ireland, but not for the northern countries, are due to the more marked improvements over the course of the last century in the childhood health conditions registered in southern Europe. It is tempting to relate this to the later economic development of the five mentioned countries but Bozzoli et al. (2007) do not find any role for national income in explaining increases in adult height.

The absence of any evidence of health gains to younger cohorts in northern European countries is perhaps surprising given continuing declines in age-specific mortality rates 
(Lafortune and Balestat, 2007) but it does not contradict two other European studies that used EQ-5D scores to scale SAH in a way that resembles what we did using the HUI3. Sutton (2004) actually found reported health to be worse among younger cohorts in the UK. Burström et al. (2005) found the same result in Sweden up to the age of 45, but beyond this age reported health was better for younger cohorts at any given age. Moreover, Crimmins (2004) showed that morbidity and disability show different trends for the elderly and it is possible that generational differences in health expectations are obscuring gains in health when measured by SAH. There is good evidence from the US of substantial year-on-year declines in age specific disability rates (Manton et al., 2007). The evidence on disability trends for other OECD countries is less consistent (Lafortune and Balestat, 2007).

We find a dramatic fall in health inequality over time in all 11 European countries studied except France, Germany, the Netherlands and the UK, where it only slightly decreased or remained stable. This finding of lower variability in health among younger cohorts is consistent with Deaton and Paxson (1998) and implies that both the US and Europe have succeeded in decreasing the degree of inequality in population health over the past century. But, consistent with other European studies (e.g. Kunst et al., 2005), there is no evidence of falling socioeconomic inequality in health across generations. While this may be considered a failure, it should be judged alongside the US evidence of increasing socioeconomic inequality (Deaton and Paxson, 1998).

We do not find consistent empirical support for Deaton and Paxson's (1998) hypothesis of rising variability in health over the life-cycle. But the prediction is confirmed for the three largest countries-France, Germany and the United Kingdom-and more emphatically so than is true for the US (Deaton and Paxson, 1998). These are not the three health systems that one would immediately think of as being least likely to provide effective health care such that health shocks accumulate and dispersion increases over the life cycle. Rather than attempt to reconcile the evidence with the hypothesis, it is perhaps more appropriate to reconsider the theory. It may well be that a model of permanent, additive and uncorrelated health shocks does not best describe the evolution of health and so cannot predict the course of its variability over the life cycle. The issue deserves further study.

Without controlling for cohort differences, we confirm US evidence (Elo and Preston, 1996; Smith and Kington, 1997; Deaton and Paxson, 1998; Smith, 2005b) of an inverse Ushaped income gradient in health that peaks around the retirement age. But after taking account of cohort effects, the inverse U-shape prevails only for British, Dutch, French, and Irish males and Danish females. In fact, while the dummies for age and cohort effects are still 
jointly significant in most countries, for males as well as for females, there is no single dominant pattern appearing for the majority of countries. In general, it simply seems much harder to disentangle age and cohort effects with sufficient precision for the adjusted concentration index than for the mean and adjusted Gini index of SAH. Already the confidence intervals for the unadjusted age profiles are larger than for the mean and adjusted Gini index, and these become even wider after correcting for cohort effects.

An important potential limitation of our study is that we identify the cohort effects from only three overlapping ages in only two adjacent cohorts. The strong assumption we have to impose is that health differences between cohorts at these three ages are representative of the differences over the whole life-span. While we have confirmed the robustness of our results for the UK using 13, rather than 8, waves, a pseudo-panel approach of a long series of cross-sections would provide more identifying information and may allow testing of whether the cohort effects merely shift and do not tilt the age profiles. It would, however, lose the cross-country dimension of the present study. A second, unavoidable limitation is that we can only correct for selective attrition based on observable, and not unobservable, characteristics. Despite these limitations, our findings appear relatively robust to a number of methodological choices and restrictions imposed by the data. Future work should concentrate on whether age and cohort profiles in health differ by socio-demographic groups within countries. This would allow consideration not only of how individuals age on average, but how the health of certain socioeconomic groups deteriorates relative to that of other SES groups (Case and Deaton, 2005).

\section{APPENDIX}

[insert Table A.1 about here]

[insert Table A.2 about here] 


\section{References}

Adler NE, Boyce T, Chesney MA, Cohen S, Folkman S, Kahn RL, Syme SL. Socioeconomic status and health. The challenge of the gradient. The American Psychologist 1994; 49: 15-24.

Atchley RC. The sociology of retirement. Halstead Press: New York, 1976.

Bardasi E, Jenkins SP, Sutherland H, Levy H, Zantomio F. British Household Panel Survey Derived Current and Annual Net Household Income Variables, Waves 1-14, 1991-2005 [computer file]. 7th Edition. University of Essex. Institute for Social and Economic Research, [original data producer(s)]. Colchester, Essex: UK Data Archive [distributor], May 2007. SN: 3909.

Barker DJP. Fetal origins of coronary heart disease. British Medical Journal 1995; 311 (6998): 171174.

Beckett M. Converging Health Inequalities in Later Life: An Artifact of Mortality Selection? Journal of Health and Social Behavior 2000; 41: 106-19.

Bozzoli C, Deaton A, Quintana-Domeque C. Child mortality, income and adult height. NBER Working Paper No. 12966. NBER: New York, 2007.

Burström K, Johannesson M, Diderichsen F. Increasing socio-economic inequalities in life expectancy and QALYs in Sweden 1980-1997. Health Economics 2005; 14: 831-850.

Case A, Deaton A. Broken down by work and sex: how our health declines. David A. Wise (ed.), Analyses in the Economics of Aging, Chicago, Chicago University Press for NBER 2005.

Case A, Fertig A, Paxson C. The lasting impact of childhood health and circumstance. Journal of Health Economics 2005; 24(2): 365-389.

Case A, Lubotsky D, Paxson C. Economic Status and Health in Childhood: The Origins of the Gradient. American Economic Review 2002; 92(5): 1308-1334.

Chandola T, Ferrie J, Sacker A, Marmot M. Social inequalities in self reported health in early old age: follow-up of prospective cohort study British Medical Journal 2007; 334: 990.

Charles KK. Is retirement depressing?: Labor force inactivity and psychological well-being in later life. NBER Working Paper 2002; No. 9033, Cambridge MA.

Cochrane JH. Time-Consistent Health Insurance. The Journal of Political Economy 1995; 103: 445473.

Crimmins E.M. Trend in the Health of the Elderly. Annual Review of Public Health 2004; 25: 79-98

Currie A, Shields MA, Wheatley Price S. The child health / family income gradient: Evidence from England. Journal of Health Economics 2007; 26: 213-232.

Deaton A. The analysis of household surveys: a microeconometric approach to development policy. The Johns Hopkins University Press: Baltimore, 1997. 
Deaton A. Income, aging, health and wellbeing around the world: Evidence from the Gallup World Poll. NBER working paper No. 13317. NBER: New York, 2007.

Deaton A, Paxson CH. Intertemporal choice and inequality. Journal of Political Economy 1994; 102: 437-467.

Deaton AS, Paxson CH. Aging and inequality in income and health. American Economic Review Papers and Proceedings 1998; 88(2): 248-253.

Diamond P. Organizing the Health Insurance Market. Econometrica 1992; 60: 1233-1254.

Elo I, Preston S. Educational differentials in mortality: United States, 1979-85. Social Science and Medicine 1996; 42(1): 47-57.

Erreygers G. Correcting the Concentration Index. Faculty of Applied Economics Research Paper 2006; No. 2006-027, University of Antwerp.

Erreygers G. Can a single indicator measure both attainment and shortfall inequality? Mimeo 2008, University of Antwerp.

EUROSTAT. Construction of weights in the ECHP. Eurostat: Luxembourg, 2003.

Fahey T, Nolan B, Maître B. Housing Expenditures and Income Poverty in EU Countries. Journal of Social Policy 2004, 33: 437-454.

Feeny D, Furlong W, Torrance GW, Goldsmith CH, Zhu Z, DePauw S, Denton M, Boyle M. Multiattribute and Single-Attribute Utility Functions for the Health Utilities Index Mark 3 System. Medical Care 2002; 40(2), 113-128.

Ferrie JE, Shipley MJ, Smith GD, Stansfeld SA, Marmot, MG. Change in health inequalities among British civil servants: the Whitehall II study. Journal of Epidemiology and Community Health 2002; 56: 922-926.

Furlong WJ, Feeny DH, Torrance GW, Barr RD. The Health Utilities Index (HUI) System for Assessing Health-Related Quality of Life in Clinical Studies. Annals of Medicine 2001; 33(5): 375-384.

Garcia J, Quintana-Domeque C. The evolution of adult height in Europe: A Brief Note, Economics and Human Biology 2007; 5(2): 340-349.

Gerdtham UG, Johannesson M. Income-related inequality in life-years and quality-adjusted lifeyears. Journal of Health Economics 2000; 19: 1007-1026.

Goodman LA. On the Exact Variance of Products. Journal of the American Statistical Association 1960; 55: 708-713.

Grossman M. On the concept of health capital and the demand for health. Journal of Political Economy 1972; 80: 223-255. 
Herd P. Do functional health inequalities decrease in old age? Research on Aging 2006; 28(3): 375392.

Hernández-Quevedo C, Jones AM, Rice N. Reporting bias and heterogeneity in self-assessed health. Evidence from the British Household Panel Survey. Cuadernos ICE 2007 forthcoming.

Horsman J, Furlong W, Feeny D, Torrance G. The Health Utilities Index (HUI): concepts, measurement properties and applications. Health and Quality of Life Outcomes 2003: 1: 54.

Idler EL, Benyamini Y. Self-rated health and mortality: a review of twenty-seven community studies. Journal of Health and Social Behavior 1997; 38: 21-37.

Jones AM, Koolman X, Rice N. Health-related non-response in the British Household Panel Survey and European Community Household Panel: using inverse-probability-weighted estimators in non-linear models. Journal of the Royal Statistical Society: Series A (Statistics in Society) 2006; 169(3): 543-569.

Kamrul Islam M, Gerdtham UG, Clarke P, Burström K. Does socioeconomic health inequality change as the population ages? Evidence from Swedish panel data. Lund University Health Economics Program Working Paper Series No. 12, 2007.

Kim J, Durden E. Socioeconomic status and age trajectories of health. Social Science and Medicine 2007; 65(12): 2489-2502.

Kunst A, Mackenbach J. Mortality Differences Associated With Educational Level in Nine Industrialized Countries. American Journal of Public Health 1994; 84: 932-37.

Kunst A, Bos V, Lahelma E, Bartley M, Lissau I, Regidor E, Mielck A, Cardano M, Dalstra J, Geurts J, Helmert U, Lennartson C, Ramm J, Spadea T, Stronegger W, Mackenbach J. Trends in socioeconomic inequalities in self-assessed health in 10 European countries. International Journal of Epidemiology 2005; 34(2): 295-305.

Lafortune G, and Balestat G. Trends in Severe Disability Among Elderly People: Assessing the Evidence in 12 OECD Countries and the Future Implications. OECD Health Working Papers 2007; 26, OECD Directorate for Employment, Labour and Social Affairs.

Le Galès C, Buron C, Costet N, Rosman S, Slama G. Development of a preference-weighted health status classification system in France: The Health Utilities Index 3. Health Care Management Science 2002; 5(1): 41-51.

Lindeboom M, van Doorslaer E. Cut-point shift and index shift in self-reported health. Journal of health economics 2004; 23: 1083-1099.

Lynch, Scott M. Cohort and Life-Course Patterns in the Relationship between Education and Health: A Hierarchical Approach. Demography 2003; 40: 309-31.

Mackenbach JP, Kunst AE, Cavelaars AE, Groenhof F, Geurts JJ. Socioeconomic inequalities in morbidity and mortality in Western Europe. The EU Working Group on Socioeconomic Inequalities in Health. Lancet 1997; 349:1655-1659. 
Manton KG, Gu XL, Lamb VL. Change in chronic disability from 1982 to 2004/2005 as measured by long term changes in function and health in the U.S. elderly population. Proceedings of the National Academy of Sciences of the United States of America 2006; 103(48): 1837418379.

Marmot M, Shipley M. Do socioeconomic differences in mortality persist after retirement? 25 Year follow up of civil servants from the first Whitehall study. British Medical Journal 1996; 313: 1177-1180.

Neuman K. Quit Your Job and Get Healthier? The Effect of Retirement on Health. Journal of Labor Research 2007, forthcoming: doi: 10.1007/s12122-007-9036-8.

Pappas G, Queen S, Hadden W, Fisher G. The Increasing Disparity in Mortality between Socioeconomic Groups in the United States, 1960 and 1986. The New England Journal of Medicine 1993; 329: 103-109.

Pauly MV, Kunreuther H, Hirth R. Guaranteed renewability in insurance. Journal of Risk and Uncertainty 1995; 10: 143-156.

Preston S, Elo I. Are Educational Differentials in Adult Mortality Increasing in the United States? Journal of Aging and Health 1995; 7: 476-496.

Ross CE, Wu CL. Education, Age, and the Cumulative Advantage in Health. Journal of Health and Social Behavior 1996; 37: 104-20.

Ruhm CJ. Good times make you sick. Journal of Health Economics 2003; 24: 637-658.

Ruhm CJ. Healthy Living in Hard Times. Journal of Health Economics 2005; 24(2); 341-363.

Shan TP, Wendt JK, Donnelly RP, de Jong G, Ahmed FS. Age at Retirement and Long Term Survival of an Industrial Population: Pospective Cohort Study. British Medical Journal 2005; 331:995, doi:10.1136/bmj.38586.448704.EO.

Smith J. Socioeconomic status and health. American Economic Review Papers and Proceedings 1998; 88(2): 192-196.

Smith J. Healthy bodies and thick wallets: the dual relation between health and socioeconomic status. Journal of Economic Perspectives 1999; 13: 145-166.

Smith JP. The impact of SES on health over the life-course. RAND Labor and Population Working Paper No. 318. RAND: Santa Monica, CA, 2005 a.

Smith JP. Unraveling the SES-health connection. Population and Development Review, Supplement Aging, health, and public policy: deomographic and economic perspectives, 2005b; 30: 108132.

Smith JP and Kington R. Demographic and Economic Correlates of Health in Old Age. Demography 1997; 34: 159-170. 
Sutton M. The effect of income on health: evidence from a British pseudo-panel. ECuity III Project Working paper 10, University of Glasgow, 2004.

Van den Berg G, Lindeboom M, Portrait, F. Economic Conditions Early in Life and Individual Mortality. American Economic Review 2006; 96 (1), 290-302.

van Doorslaer E, Jones AM. Inequalities in self-reported health: validation of a new approach to measurement. Journal of health economics 2003; 22: 61-87.

van Doorslaer E, Koolman X. Explaining the differences in income-related health inequalities across European countries. Health Economics 2004; 13: 609-628.

van Doorslaer E, Wagstaff A, Bleichrodt H, Calonge S, Gerdtham U-G, Gerfin M, Geurts J, Gross L, Häkkinen U, Leu RE, O'Donnell O, Propper C, Puffer F, Rodriguez M, Sundberg G, Winkelhake O. Income-related inequalities in health: some international comparisons Journal of Health Economics 1997; 16(1): 93-112.

Van Ourti T. Socio-economic inequality in ill-health amongst the elderly. Should one use current or permanent income? Journal of Health Economics 2003; 22: 219-241.

Wagstaff A, Paci P, van Doorslaer E. On the measurement of inequalities in health. Social Science and Medicine 1991; 33(5): 545-557.

Weiss Y, Lillard LA. Experience, vintage and time effects in the growth of earnings: American Scientists, 1960-1970. Journal of Political Economy 1978; 86: 427-47.

Wilson A, Shuey K, Elder G. Cumulative advantage processes as mechanisms of inequality in life course health. American Journal of Sociology 2007; 112(6): 1886-1924. 
Figure 1: Sensitivity of age profiles to the method of scaling self assessed health (SAH), Males, 2001 Canadian Community Household Survey

SAH categories scaled 1-5

Mean Health
Adjusted Gini
Adjusted
Concentration
Index
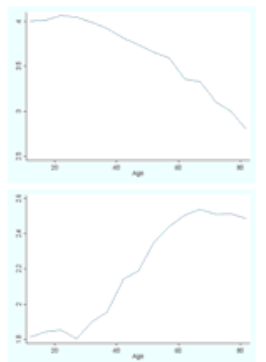

SAH category HUI3 score
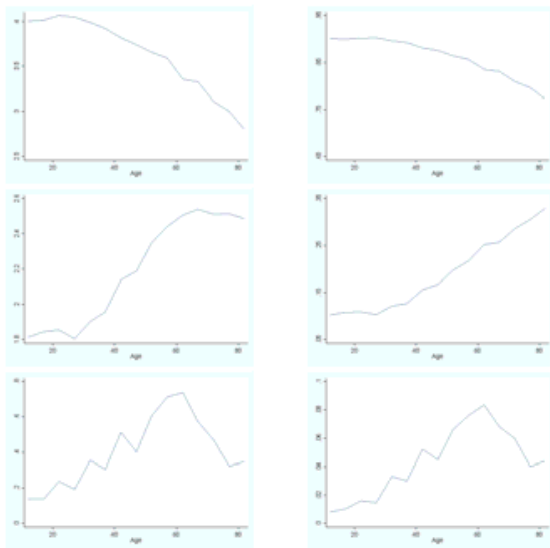

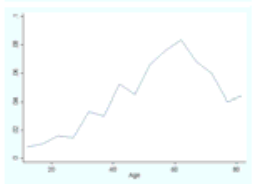

SAH category, age-sex specific HUI3 score

Actual HUI3 score
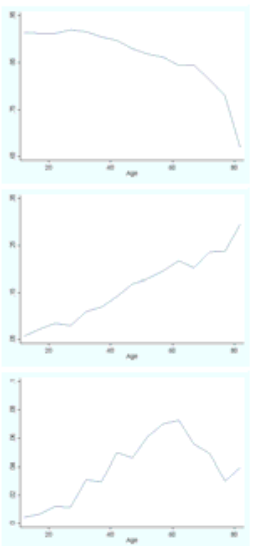
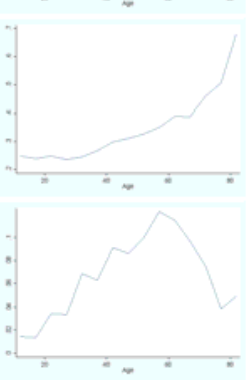

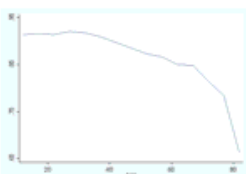


Figure 2: Age differences in mean, adjusted Gini, and adjusted Concentration Index of self assessed health scaled by age-sex specific HUI3 scores in 11 EU countries, for males (top) and females (bottom) (1994-2001)

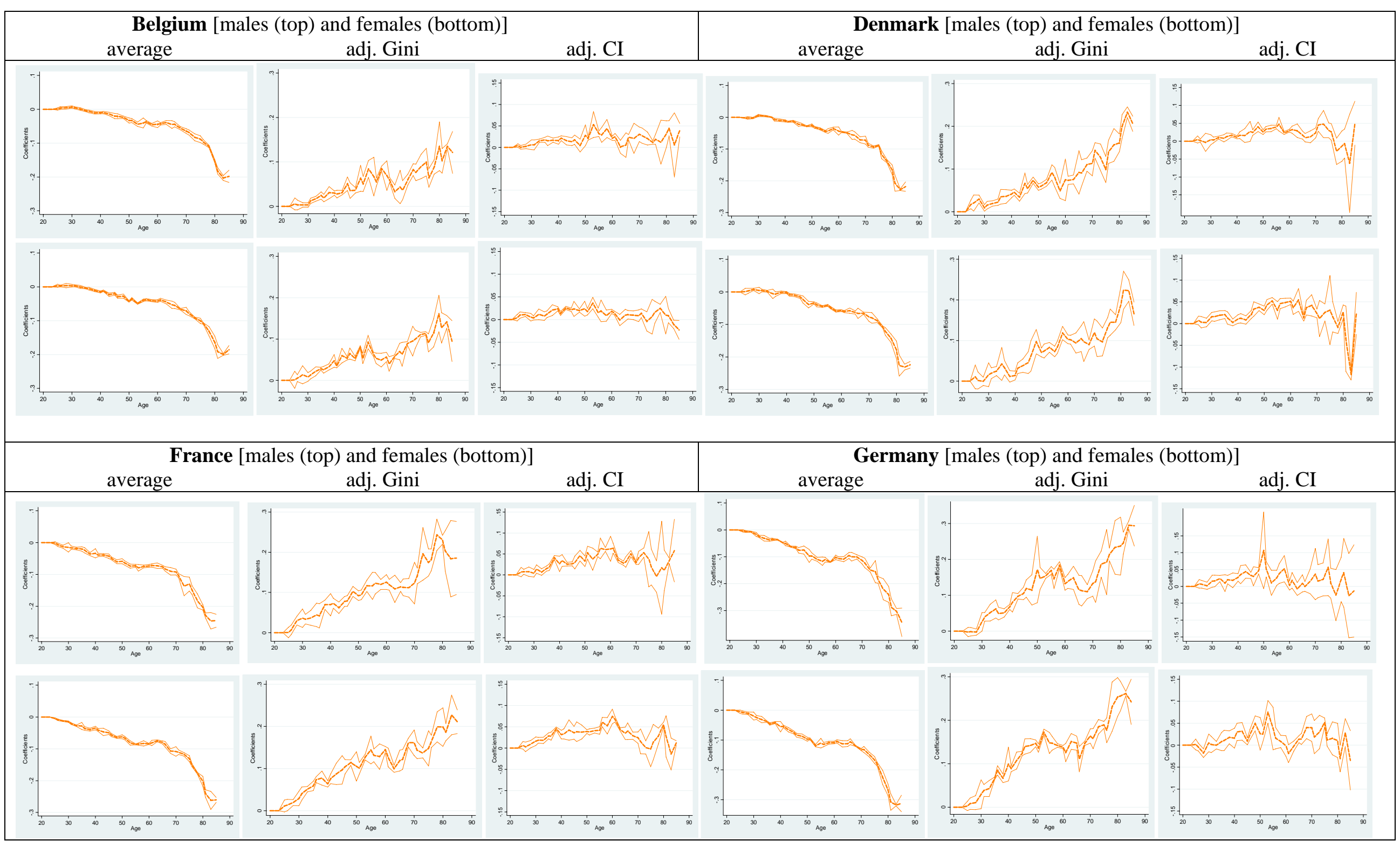




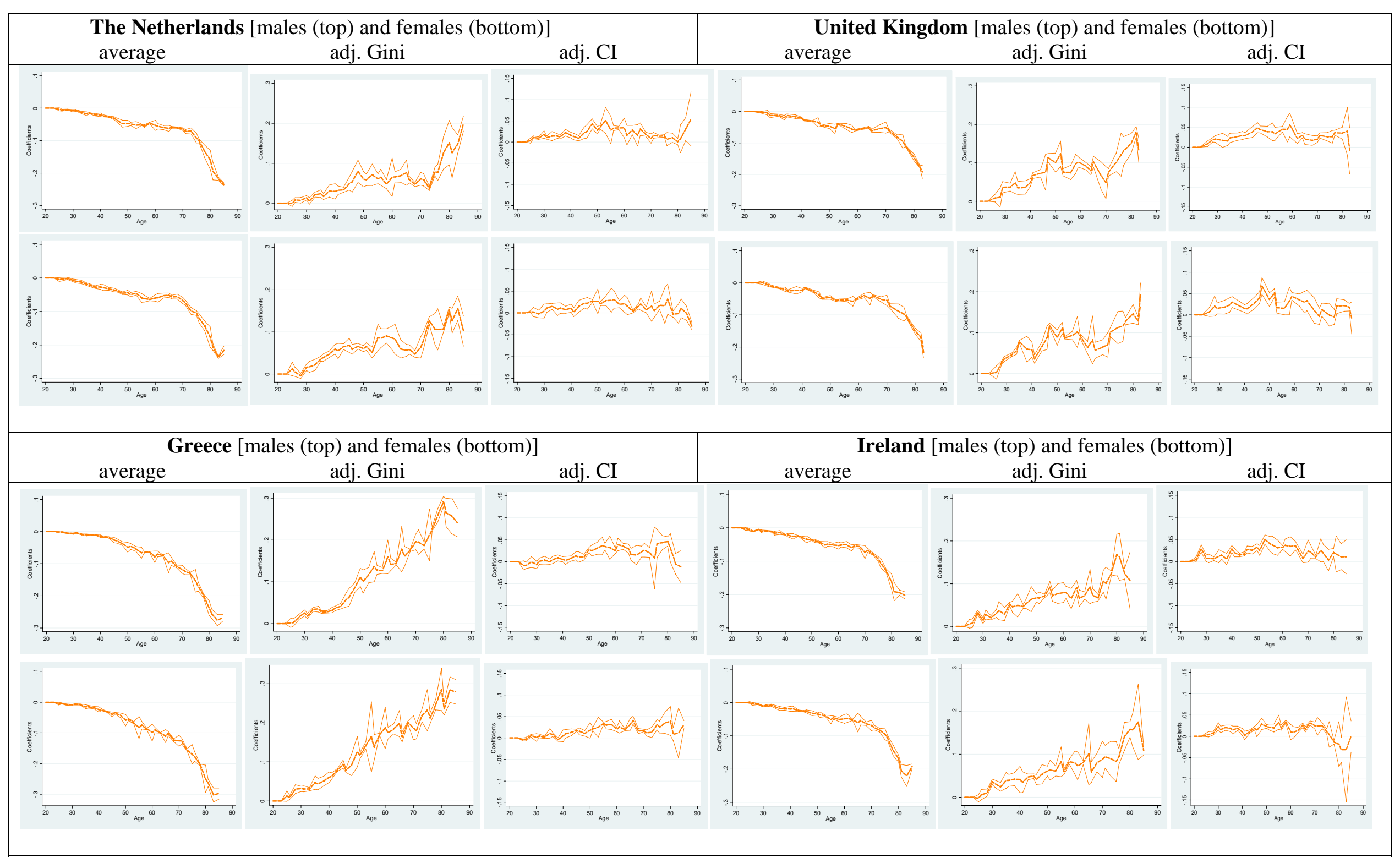




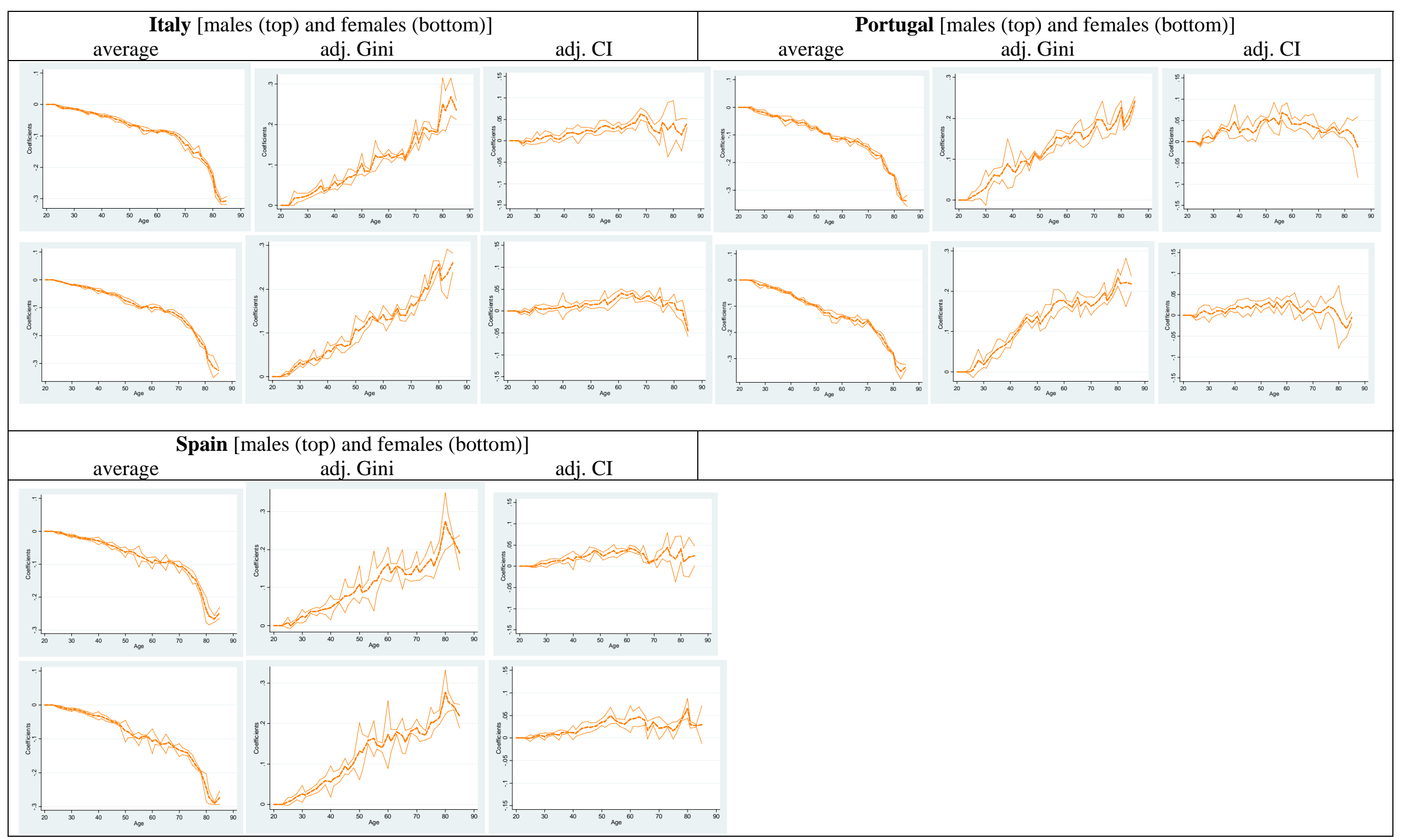


Figure 3: Life cycle (light, dotted) and cohort (dark, solid) profiles of mean, adjusted Gini, and adjusted Concentration Index of selfassessed health scaled by age-sex specific HUI3 scores in 11 EU countries, separately for males (top) and females (bottom) (1994-2001)

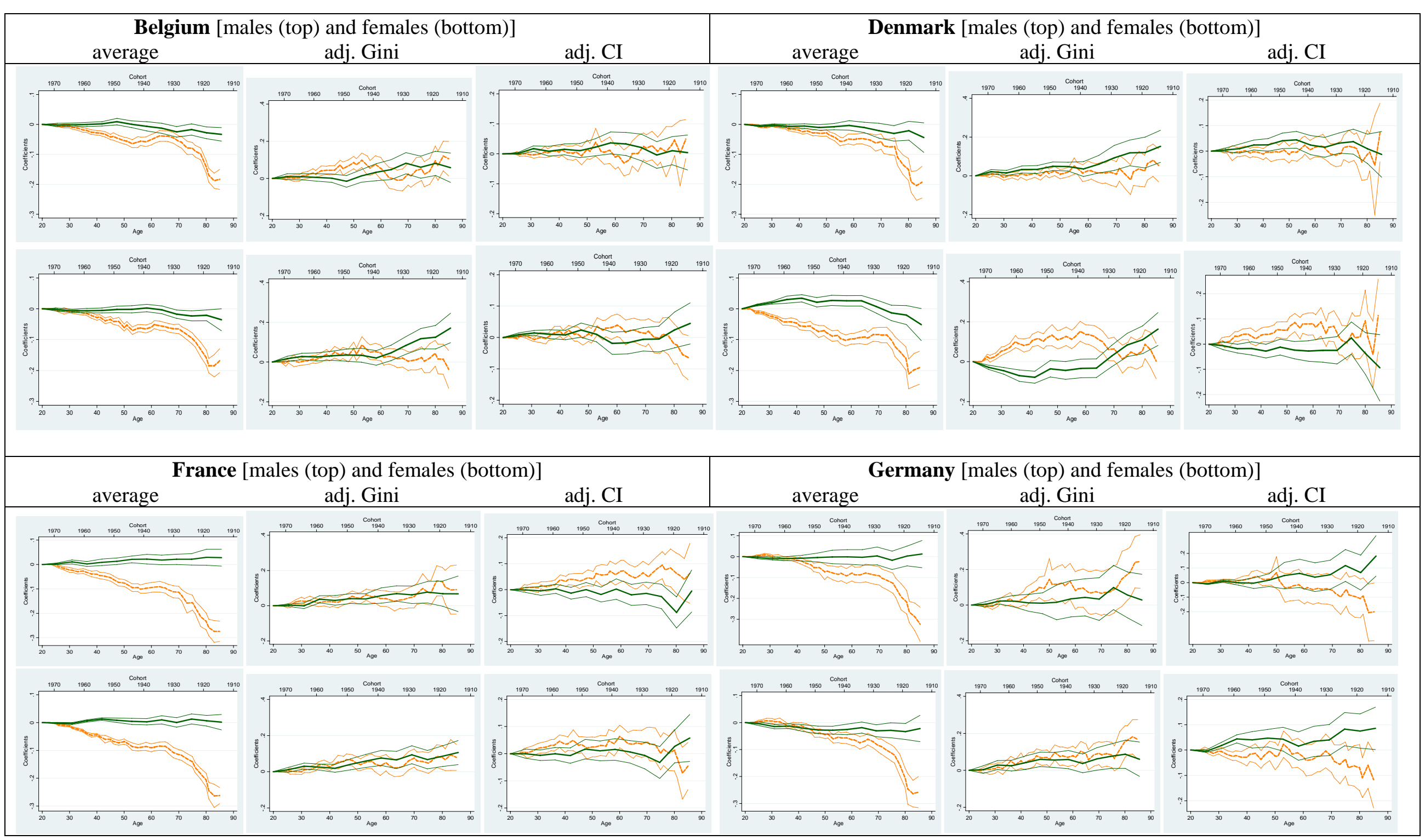




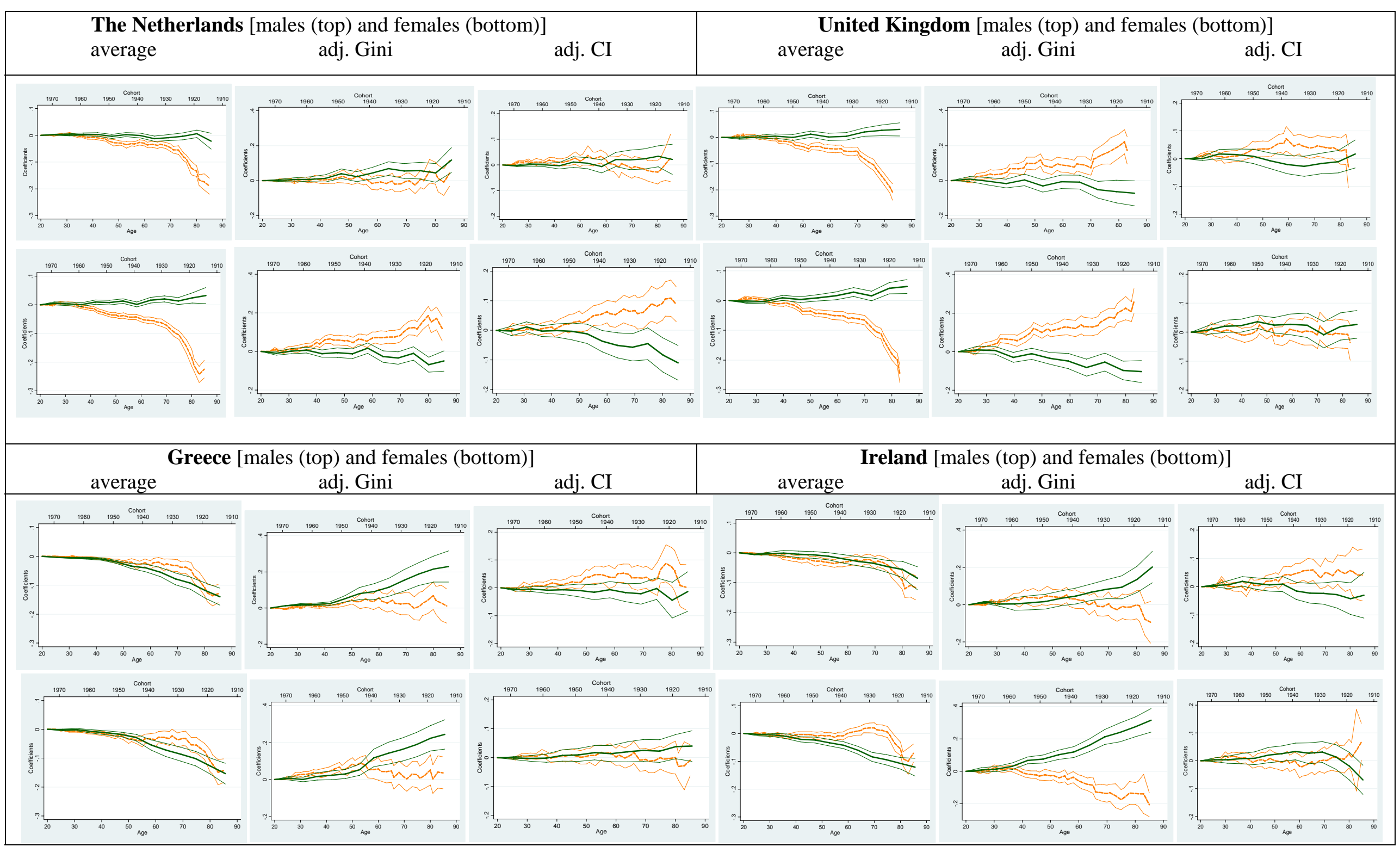




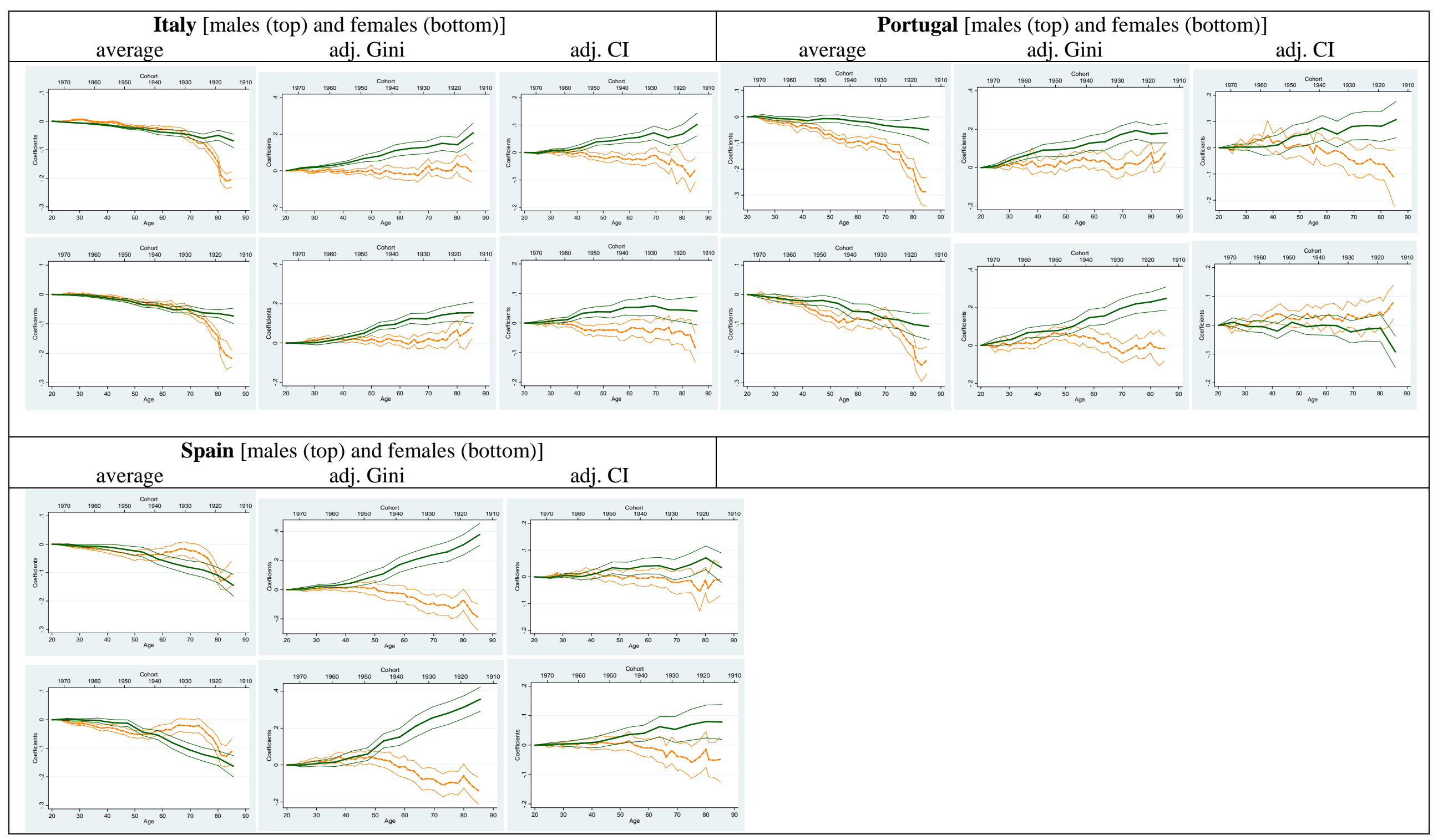


Table 1: Average ages of the three youngest cohorts across the panel

\begin{tabular}{|l|lllll|lllll|llllll|}
\hline Cohort 1 & 20 & 21 & 22 & 23 & 24 & 25 & 26 & 27 & & & & & \\
\hline Cohort 2 & & & & & & 25 & 26 & 27 & 28 & 29 & 30 & 31 & 32 & & \\
\hline Cohort 3 & & & & & & & & & & 30 & 31 & 32 & 33 & 34 \\
\hline
\end{tabular}


Table A.1: Descriptive Statistics

\begin{tabular}{|c|c|c|c|c|c|c|c|c|c|c|c|}
\hline & FRA & GER & NL & UK & GR & ITA & POR & SPA & $\mathrm{BE}$ & DK & IRE \\
\hline Observations Wave 1 & 13166 & 11829 & 9048 & 7809 & 11859 & 16657 & 10936 & 16883 & 6427 & 5652 & 9472 \\
\hline Observations Wave 2 & 11623 & 11041 & 8140 & 6841 & 10506 & 15488 & 10208 & 14006 & 5749 & 4919 & 7572 \\
\hline Observations Wave 3 & 11039 & 10518 & 7786 & 6618 & 9640 & 14967 & 9671 & 13066 & 5316 & 4385 & 6405 \\
\hline Observations Wave 4 & 9926 & 10053 & 7347 & 6359 & 8877 & 13672 & 9281 & 11754 & 4812 & 3956 & 5678 \\
\hline Observations Wave 5 & 9156 & 9413 & 6769 & 6105 & 8837 & 14239 & 10019 & 11835 & 4809 & 3851 & 5462 \\
\hline Observations Wave 6 & 8523 & 8948 & 6200 & 5550 & 8331 & 13553 & 9762 & 11198 & 4443 & 3623 & 4621 \\
\hline Observations Wave 7 & 7902 & 8480 & 5731 & 5287 & 8104 & 12692 & 9461 & 10424 & 4150 & 3425 & 3720 \\
\hline Observations Wave 8 & 7601 & 8070 & 5106 & 5021 & 8012 & 11516 & 9237 & 10044 & 3736 & 3368 & 3248 \\
\hline Mean SAH ${ }^{1}$ & 2.41 & 2.66 & 2.16 & 2.19 & 1.91 & 2.38 & 2.81 & 2.34 & 2.13 & 1.86 & 1.79 \\
\hline Mean HUI3 ${ }^{2}$ & 0.87 & 0.84 & 0.90 & 0.88 & 0.89 & 0.87 & 0.83 & 0.87 & 0.89 & 0.90 & 0.91 \\
\hline Mean income ${ }^{3}$ & 184928 & 57515 & 55377 & 19841 & 4295866 & 39169 & 2339057 & 2876558 & 1224194 & 249015 & 21579 \\
\hline Mean age & 47.55 & 46.16 & 47.43 & 47.31 & 49.54 & 46.30 & 49.11 & 47.66 & 47.35 & 46.86 & 46.15 \\
\hline Proportion of males & 0.47 & 0.48 & 0.47 & 0.47 & 0.47 & 0.49 & 0.48 & 0.48 & 0.47 & 0.49 & 0.49 \\
\hline
\end{tabular}

Notes:

1. Self Assessed Health on five-point scale with 'very bad' given a value of 1 and 'very good' a value of 5 .

2. Health Utility Index Mark 3.

3. National currency units. 
Table A.2: Joint significance tests (p-values) per statistic of the age and cohort dummies separately for males (left) and females (right)

\begin{tabular}{|c|c|c|c|c|c|c|c|}
\hline Country & Age/Cohort & Mean & Adj. Gini & Adj. CI & Mean & Adj. Gini & Adj. $C l$ \\
\hline \multirow[t]{2}{*}{ France } & Age & 0.0000 & 0.0000 & 0.0000 & 0.0000 & 0.0000 & 0.0000 \\
\hline & Cohort & 0.0000 & 0.0000 & 0.0000 & 0.0000 & 0.0000 & 0.0000 \\
\hline \multirow[t]{2}{*}{ Germany } & Age & 0.0000 & 0.0000 & 0.0665 & 0.0000 & 0.0000 & 0.0000 \\
\hline & Cohort & 0.0001 & 0.0009 & 0.0000 & 0.0000 & 0.0005 & 0.0000 \\
\hline \multirow[t]{2}{*}{ Netherlands } & Age & 0.0000 & 0.0000 & 0.0000 & 0.0000 & 0.0000 & 0.0000 \\
\hline & Cohort & 0.0000 & 0.0000 & 0.0011 & 0.0000 & 0.0000 & 0.0000 \\
\hline \multirow[t]{2}{*}{ UK } & Age & 0.0000 & 0.0000 & 0.0002 & 0.0000 & 0.0000 & 0.0000 \\
\hline & Cohort & 0.0000 & 0.0000 & 0.0115 & 0.0000 & 0.0000 & 0.0000 \\
\hline \multirow[t]{2}{*}{ Greece } & Age & 0.0000 & 0.0000 & 0.0001 & 0.0000 & 0.0000 & 0.0000 \\
\hline & Cohort & 0.0000 & 0.0000 & 0.0028 & 0.0000 & 0.0000 & 0.5484 \\
\hline \multirow[t]{2}{*}{ Italy } & Age & 0.0000 & 0.0000 & 0.0000 & 0.0000 & 0.0000 & 0.0000 \\
\hline & Cohort & 0.0000 & 0.0000 & 0.0000 & 0.0000 & 0.0000 & 0.0012 \\
\hline \multirow[t]{2}{*}{ Portugal } & Age & 0.0000 & 0.0000 & 0.0000 & 0.0000 & 0.0000 & 0.0000 \\
\hline & Cohort & 0.0000 & 0.0000 & 0.0000 & 0.0000 & 0.0000 & 0.0000 \\
\hline \multirow[t]{2}{*}{ Spain } & Age & 0.0000 & 0.0000 & 0.0483 & 0.0000 & 0.0000 & 0.0150 \\
\hline & Cohort & 0.0000 & 0.0000 & 0.0000 & 0.0000 & 0.0000 & 0.0863 \\
\hline \multirow[t]{2}{*}{ Belgium } & Age & 0.0000 & 0.0000 & 0.0229 & 0.0000 & 0.0000 & 0.0000 \\
\hline & Cohort & 0.0000 & 0.0001 & 0.0000 & 0.0000 & 0.0000 & 0.0000 \\
\hline \multirow[t]{2}{*}{ Denmark } & Age & 0.0000 & 0.0000 & 0.0000 & 0.0000 & 0.0000 & 0.0000 \\
\hline & Cohort & 0.0006 & 0.0000 & 0.0031 & 0.0000 & 0.0000 & 0.0074 \\
\hline \multirow[t]{2}{*}{ Ireland } & Age & 0.0000 & 0.0000 & 0.0000 & 0.0000 & 0.0000 & 0.0000 \\
\hline & Cohort & 0.0000 & 0.0000 & 0.0022 & 0.0000 & 0.0000 & 0.0000 \\
\hline
\end{tabular}




\section{Notes}

${ }^{1}$ Deaton and Paxson (1998) propose that the evolution of health is given by $h_{i t}=h_{i t-1}+u_{i t}$ (Deaton and Paxson, 1994). Assuming zero covariance between lagged health and the health shock $(u), \operatorname{var}_{t}(h)-\operatorname{var}_{t-1}(h)=\sigma_{u}^{2}>0$ if health shocks are not perfectly correlated across individuals. But if health evolves according to a depreciation process, $h_{i t}=h_{i t-1}\left(1-\delta_{i t}\right)$, where $\delta_{i t} \in[0,1)$ represents the stochastic rate of depreciation that is assumed independent of the level of health, then $\operatorname{var}\left(h_{i t}\right)-\operatorname{var}\left(h_{i, t-1}\right)=\underbrace{-2 \bar{\delta}_{t} \operatorname{var}\left(h_{i, t-1}\right)}_{\text {term1 }}+\underbrace{E\left(h_{i, t-1}^{2}\right) E\left(\delta_{i t}^{2}\right)-\left(E\left(h_{i, t-1}\right)\right)^{2} \bar{\delta}_{t}^{2}}_{\text {term2 }}$

(Goodman, 1960). Term 1 in the latter equation is negative, while term 2 is positive; which is larger depends upon the distribution of $\delta_{i t}$. For example, if the depreciation rate is a constant, then the variance will be decreasing over time (Deaton and Paxson, 1994).

${ }^{2}$ Burström et al. (2005) do report that inequalities in life expectancy and QALYs have been increasing over time. Pappas et al. (1993) also find increasing socioeconomic inequalities in mortality in the US.

${ }^{3}$ The BHPS only covers Great Britain, but for convenience we refer to the UK throughout the text.

${ }^{4}$ The OECD scale gives a weight of 1.0 to the first adult, 0.5 to the second and each subsequent person aged 14 and over, and 0.3 to each child aged under 14 in the household.

${ }^{5}$ The SAH question in France and Germany was consistent with the other ECHP countries but a 6 and 10 point scale respectively was used and responses were recoded into the common 5 point scale by Eurostat.

${ }^{6}$ The adjusted concentration index is defined as $4 \frac{E\left(h_{i}\right)}{b_{h}-a_{h}} C I\left(h_{i}\right)$ where $C I\left(h_{i}\right)$ is the standard concentration index (Wagstaff et al., 1991), and $b_{h}$ and $a_{h}$ are the maximum and minimum of the health variable $h_{i}$.

${ }^{7}$ Define $\tilde{h}_{i}=c+d h_{i}, c>0, d>0$, then, of course, $E\left(\tilde{h}_{i}\right)=c+d E\left(h_{i}\right)$. The value of mean health depends on the values of $c$ and $d$, but its life cycle profile, represented by the difference in mean health between age groups, is invariant up to multiplication by the scalar $d$. The latter does not hold for the standard concentration and Gini indices (Wagstaff et al., 1991) since $C I\left(\tilde{h}_{i}\right)=\frac{d E\left(h_{i}\right)}{c+d E\left(h_{i}\right)} C I\left(h_{i}\right) \neq c+d C I\left(h_{i}\right)$. For the adjusted concentration and Gini indices (Erreygers, 2006, 2008) we have an even stronger result since their values are independent from $c$ and $d$, i.e. $\frac{4 E\left(\tilde{h}_{i}\right) C I\left(\tilde{h}_{i}\right)}{\tilde{b}_{h}-\tilde{a}_{h}}=\frac{4 E\left(c+d h_{i}\right) C I\left(c+d h_{i}\right)}{c+d b_{h}-c-d a_{h}}=\frac{4\left[c+d E\left(h_{i}\right)\right]}{d b_{h}-d a_{h}} \frac{d E\left(h_{i}\right) C I\left(h_{i}\right)}{c+d E\left(h_{i}\right)}=\frac{4 E\left(h_{i}\right) C I\left(h_{i}\right)}{b_{h}-a_{h}}$.

${ }^{8}$ The income measure in the CCHS is not continuous, but in six categories. We neglect its ordinal nature while calculating the adjusted concentration index since our purpose is simply to illustrate the advantage of using SAH category, age-sex specific means of HUI3.

${ }^{9}$ For the mean, the age profile drawn from the SAH category, age-sex specific means of HUI3 is necessarily identical to that drawn from the observation specific HUI3 scores.

${ }^{10}$ More precisely, dummies are defined as follows: dummy1 (age=20), dummy2 (age=21,22), dummy3 (age=23,24), dummy4 (age=25), dummy5 (age=26,27), etc. Note that these age dummies only cover the average age of the cohort in a particular wave. So there is no dummy for ages 18-19. For the UK this structure is not suitable since the dummies do not correctly embed the overlap in ages between five year birth cohorts given that one wave of the panel is omitted. We therefore used six year birth cohorts and a combination of 1,2 and 3 year age dummies for the UK. This ensures an overlap of three years for consecutive cohorts, as for the other countries.

${ }^{11}$ Observations that join the panel after the first wave are excluded because their inclusion would be inconsistent with the cohort nature of the analysis and it would render the method, described below, of correcting for attrition infeasible.

${ }^{12}$ Since the dependent variables are constructed for cohorts of individuals of different sizes, we use robust standard errors to correct for the resulting heteroskedasticity, if any.

${ }^{13}$ For males, only Denmark, Italy, Portugal and the UK have significant period effects for the mean. Only Spain has significant period effects for the adjusted Gini index. The effects for the adjusted concentration index are significant for British, German, and Portuguese males. For females, significance of the period effects is found for Denmark, France, Germany, Greece, Italy, Portugal, Spain and UK for the mean. For the Gini index German, Greek, Italian, and Spanish females have significant period effects. Finally, for the concentration index only German females have significant period effects. 